\title{
James E. Fowler, Voicing desire. Family and Sexuality in Diderot's Narrative
}

\section{Mark Darlow}

\section{(2) OpenEdition}

10 Journals

\section{Édition électronique}

URL : https://journals.openedition.org/studifrancesi/40777

DOI : $10.4000 /$ studifrancesi.40777

ISSN : 2421-5856

Éditeur

Rosenberg \& Sellier

\section{Édition imprimée}

Date de publication : 1 juillet 2004

Pagination : 199

ISSN : 0039-2944

\section{Référence électronique}

Mark Darlow, « James E. Fowler, Voicing desire. Family and Sexuality in Diderot's Narrative », Studi Francesi [En ligne], 142 (XLVIII | I) | 2004, mis en ligne le 30 novembre 2015, consulté le 09 septembre 2021. URL : http://journals.openedition.org/studifrancesi/40777 ; DOI : https://doi.org/10.4000/ studifrancesi.40777

Ce document a été généré automatiquement le 9 septembre 2021.

\section{(c)}

Studi Francesi è distribuita con Licenza Creative Commons Attribuzione - Non commerciale - Non opere derivate 4.0 Internazionale. 


\title{
James E. Fowler, Voicing desire. Family and Sexuality in Diderot's Narrative
}

\author{
Mark Darlow
}

\section{RÉFÉRENCE}

JAMES E. FOWLER, Voicing desire. Family and Sexuality in Diderot's Narrative, Oxford, Voltaire Foundation, 2002, ('Vif'), pp. ix-169.

1 Voicing desire que nous présentons avec un retard impardonnable consiste en une étude psychanalytique des œuvres narratives majeures de Diderot et prend comme outil méthodologique principal la pensée de Freud, même si certains concepts lacaniens sont également employés. James Fowler explique que son intention n'est pas de proposer une psychanalyse de Diderot lui-même, mais bien plutôt d'effectuer une analyse des personnages et des principaux éléments structuraux des récits.

2 A travers l'étude de cinq textes, qui font chacun l'objet d'un chapitre, l'auteur cherche à démontrer que les relations familiales, qui s'articulent autour du désir, constituent à chaque fois un élément structurant majeur. Dans l'introduction, Fowler insiste sur la cohérence de ce corpus, qu'il oppose à l'hétérogénéité supposée caractériser l'œuvre de Diderot; cette cohérence résulte de la présence de la sexualité en tant que force majeure qui détermine l'expérience privée comme la vie sociale. La notion de voix (Voicing Desire) se rapporte à un trait important, qui se retrouve dans les cinq textes, à savoir l'irruption du désir au sein d'un discours qui cherche à le nier. Dans Les Bijoux indiscrets, l'accent est mis non pas tant sur la sexualité féminine, objet classique des travaux sur cette œuvre, que sur le désir masculin. Le discours de Mangogul polarise la féminité autour de deux catégories: la maman et la putain. La présence de cette dichotomie tire l'œuvre vers des structures œdipiennes et le discours officiel, prétendument objectif, de Mangogul est miné par l'anxiété de la castration. Pour 
Fowler, les Bijoux indiscrets sont ainsi à considérer comme une clé pour les œuvres plus tardives, dans la mesure où ils consistent en un récit du désir et de la 'voix' de la sexualité qui va à l'encontre d'un discours officiel. Quant aux chapitres suivants, qui traitent respectivement de l"espèce de roman' (Diderot) constitué par Le Fils naturel et ses annexes, La Religieuse, Jacques le fataliste et Le Neveu de Rameau, il s'agit surtout de lectures œdipiennes, où la tension entre deux personnages et la question de la rivalité sous-tendue par le désir est admirablement mise en lumière.

La conclusion (pp. 145-57) propose une explication méthodologique où l'auteur montre comment les concepts de personnage et de structure narrative sont intimement liés: l'auteur se démarque ici des lectures narratologiques informées par la psychanalyse lacanienne et des théories de Peter Brooks, qui prétendent analyser la structure narrative sans référence à la psychanalyse du caractère. En tant que justification de l'approche méthodologique des chapitres précédents, chacun argumenté de façon convaincante, cette conclusion n'est peut-être pas indispensable; mais elle sert à recentrer le propos et à situer de façon particulièrement claire cette étude dans le champ de la narratologie psychanalysante. 